\title{
Mathematical Simulating of the Process of Friction Stir Welding for the Manufacture of Tank Bottoms in Aerospace Construction
}

\author{
Pavel V. Kruglov ${ }^{1 *}$, Alexey G. Ponarin ${ }^{2}$, and Irina A. Bolotina ${ }^{1}$ \\ ${ }^{1}$ Bauman Moscow State Technical University, 2nd Baumanskaya str., 5/1, 105005, Moscow, Russia \\ ${ }^{2}$ JSC "NPO VNIIEM”, Moscow, Russia
}

\begin{abstract}
In modern aerospace technology, one of the perspective ways of assembly parts of thin metal plates is friction stir welding. The advantage of this method is the higher strength of the welds of aluminum alloy joints, compared with the traditional MIG welding for the assembly of rockets and space constructions. However, the lack of friction stir welding is a necessity of formation of the system "machine -tool - part" significantly more effort, which is caused by the need to stir the material in the weld zone in a plastic state. Friction stir welding is used to connect the individual elements of tanks and bodies, in particular, panels, elements of the bottoms with each other. In this paper, is consider the typical design for rocket and space technology bottoms of large tanks. For industrial robot equipped with a special head for friction welding with mixing, a mathematical model of obtaining a spherical bottom from individual segments is proposed. The paper presents a mathematical model describing the geometry of a spherical bottom with a flap articulation and a working zone of an industrial robot, which allows defining constraints on process operation continuous seam welding for standard designs of bottoms and hulls of rocket and space technology. The dependences allowing determining the initial position of the robot relative to the bottom for performing friction stir welding of the continuous seam are proposed.
\end{abstract}

\section{Introduction}

Currently, one of the most promising ways to connect thin metal plates is friction stir welding [1-4]. The advantage of this method is higher strength of welds of aluminum alloy joints used in rocket and space engineering constructions compared to MIG welding [4-9]. At the same time, the feature of the method is the presence of large force factors in the system "machinetool-part".

For the manufacture of structures of tanks and hulls of rocket and space technology, which, as a rule, have a thin shell spherical shape, it is necessary to develop specialized equipment for friction stir welding $[4,8,9]$. To obtain the longitudinal and transverse (circumferential) welds of the tanks developed specialized equipment. For production of

* Corresponding author: kpv17@bmstu.ru 
longitudinal seams of shells installations with a vertical arrangement of a welded seam are used. In such installations, the welding head is moved on a special support from top to bottom. To obtain circular joints, machines are used with the basing of internal power elements in a basket that maintains the constancy of the cross-section profile of the tank.

For the manufacture of tank bottoms and hulls, the domestic industry is developing specialized technological equipment. At production of bottoms it is necessary to consider features of geometry of the bottom, presence on its surface of branch pipes, hatches. In the mathematical model of limiting geometrical parameters of welding of branch pipes to the bottoms of rockets stated in [8], the geometry of the bottom, branch pipe, head for friction stir welding is considered. At the same time welding of elements of bottoms among themselves demands further studying.

In this paper, is consider the typical design of the bottoms of rocket and space technology, describes the basic technological equipment for the manufacture of friction stir welding $[10,11]$, and, for an industrial robot equipped with a head for friction stir welding [12], developed a mathematical model of obtaining the bottom of the individual elements. On the basis of the model, the geometric possibilities of friction stir welding of the bottoms of different designs are estimated.

The large dimensions of tanks and hulls of rocket and space technology lead to the need for dividing the bottoms into separate elements. The most characteristic is the petal (Fig.1, a) and segmental division (Fig. 1, b) [9]. The bottom, as a rule, has a spherical or ellipsoidal shape. The diameter of the bottom can reach 7.7 meters (fuel tank "Energy"), $8.5 \mathrm{~m}$ (fuel tank system "Space Shuttle") [9]. For welding of such bottoms specialized large-size equipment were used. This paper discusses the technical possibilities of manufacturing bottoms and petal partitioning in the dimensions of modern launch vehicles (diameter up to $4.0 \mathrm{~m}$ ).
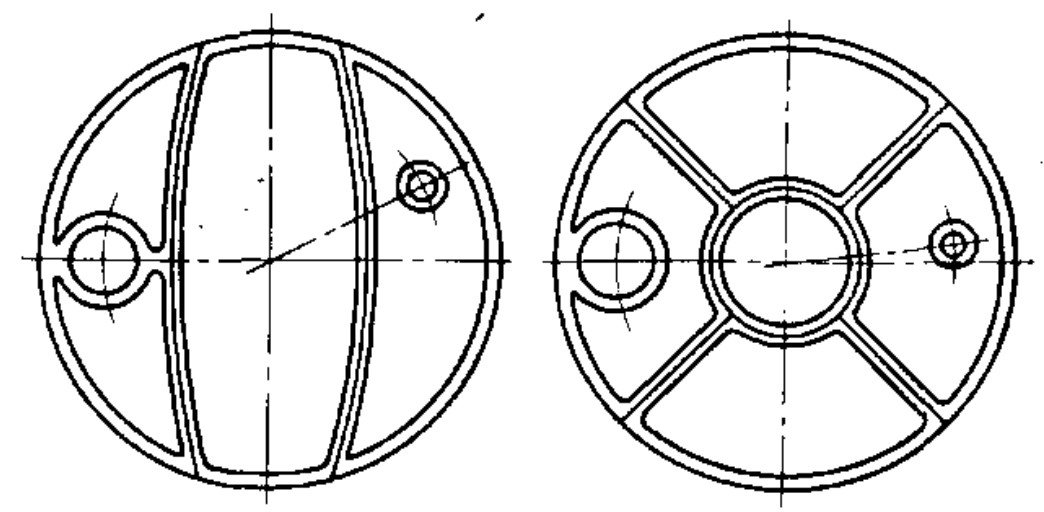

Fig. 1. Variants of petal (left) and segmental (right) division of the bottom of large sizes.

\section{Overview of friction stir welding equipment}

To assess the possibility of manufacturing bottoms by friction stir welding, it will conduct a brief review of industrial process equipment produced by leading manufacturers [9-12].

Depending on the purpose, industrial equipment for friction stir welding is divided into:

- Small-sized 2-3 coordinate machines

- Portal type machines

- Machines for welding of panels

- Industrial robot

Small-sized 2-3 coordinate machines (Fig.2) designed for welding products of small dimensions, have a limited working area. 


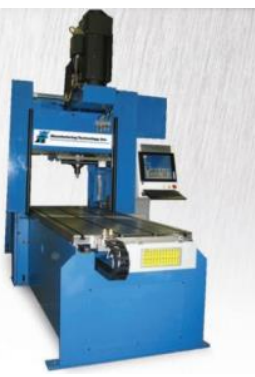

(a)

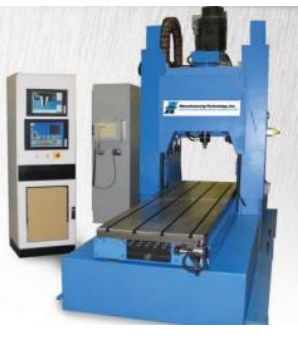

(b)

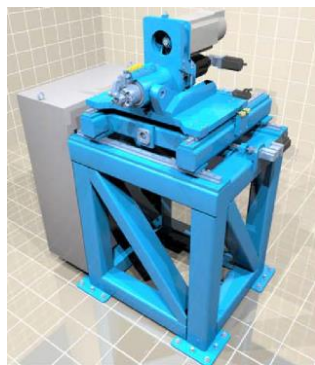

(c)

Fig. 2. Small-sized machines of firms MTI (USA) (a) and (b) and Novatech (USA) (c).

Portal type machines ( 5 coordinate) are used for welding parts of complex shape, with a large thickness of the welded edges (Fig.3). Large efforts arising in the process of welding of such seams require the use of particularly rigid structures of machine equipment and devices, which is implemented in the portal scheme. In addition, such welding plants are equipped with a rotary welding head to expand their capabilities.

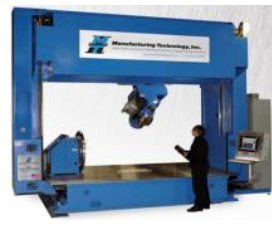

(a)

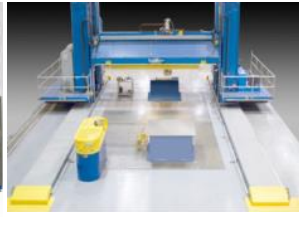

(b)

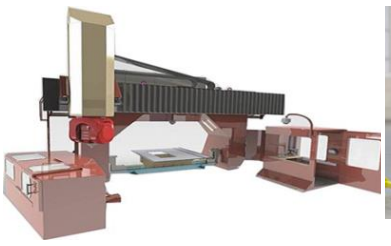

(c)

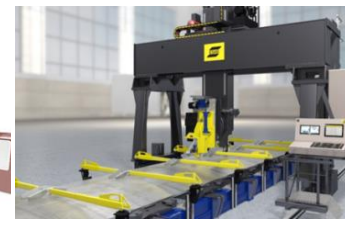

(d)

Fig. 3. Portal type machines from MTI (USA) (a), Novatech (USA) (b), Huge (Switzerland) (c), ESAB (Sweden) (d).

Equipment for welding of the panels (Fig.4) are used for the manufacture of large panels with a large length of the resulting weld and have large dimensions and significant stiffness.

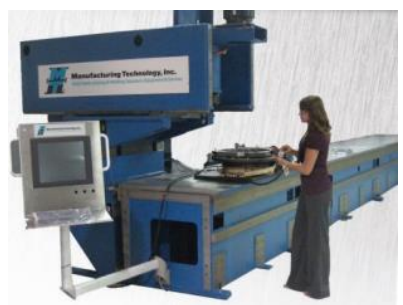

(a)

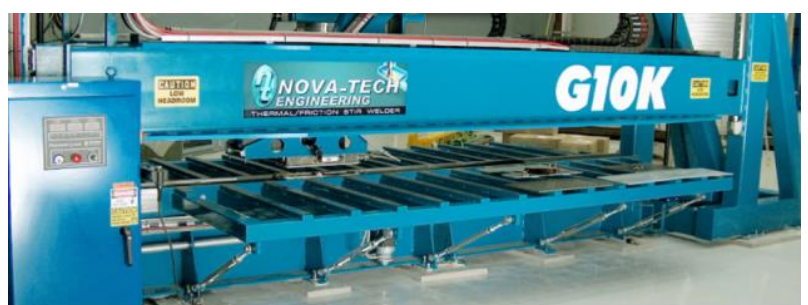

(b)

Fig. 4. Panel welding machines from MTI (USA) (a) and Novatech (USA) (b).

Industrial robots have wide kinematic possibilities and some models of robots of ESAB, ABB, KUKA firms are equipped with replaceable heads for friction stir welding (Fig.5). Limitations of the use of such equipment are the rigidity of the robot structure associated with the applied forces in the welding zone, and geometric restrictions on the working area of the robot. The efforts in the area of the weld impact strength and plastic properties of a welded material, its thickness, temperature of material, process parameters - speed, head movement, frequency of rotation and other parameters. 


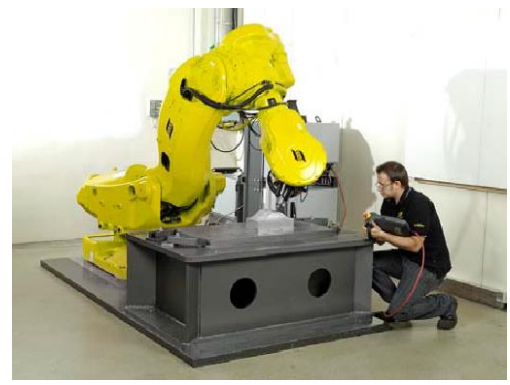

(a)

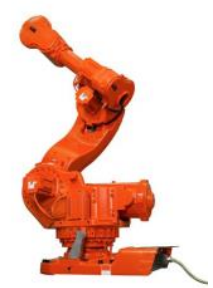

(b)

Fig. 5. Industrial robots equipped with friction stir welding head ESAB Rosio (Sweden) (a) and ABB IRB 7600 (Switzerland) (b).

Figure 6 shows the geometric constraints of the ESAB Rosio robot working area [12]. The working area of manipulators can be represented as a three-dimensional working area.

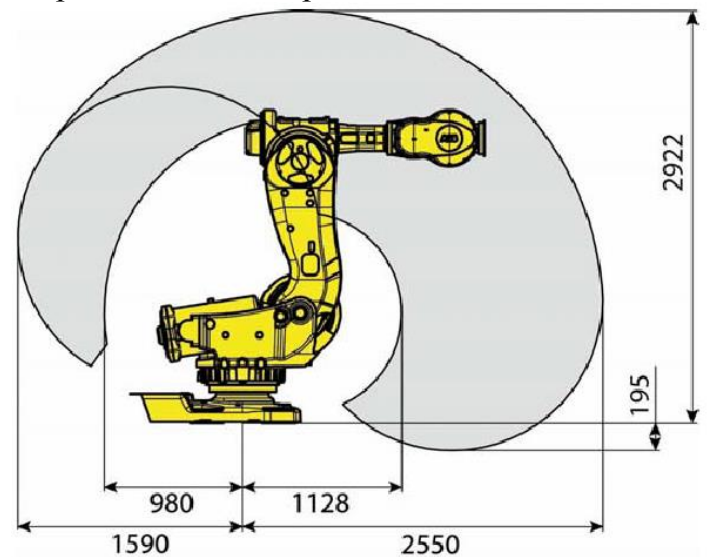

Fig. 6. Working area of ESAB Rosio robot (Sweden).

Now the robots is a very effective way to manufacturing parts of aerospace constructions [13-18]. However, in addition to geometrical problem, can be solved and thermic, stresses, quality's problem [19-24]. For solve this problem used simulation for friction stir welding in various representation $[8,9,13,25]$.

\section{Methods}

When analyzing industrial equipment, it was noted that the domestic industry does not produce specialized plants for the manufacture of bottoms. In this paper, is consider the possibility of using an industrial robot equipped with a friction welding head with mixing, to obtain the bottoms of rocket and space technology from individual elements. For this purpose, a mathematical model of the working area of the robot, a model of the geometry of the weld at different ways of dividing the bottom and the geometric limitations of the friction stir welding are determined (Fig.7). 

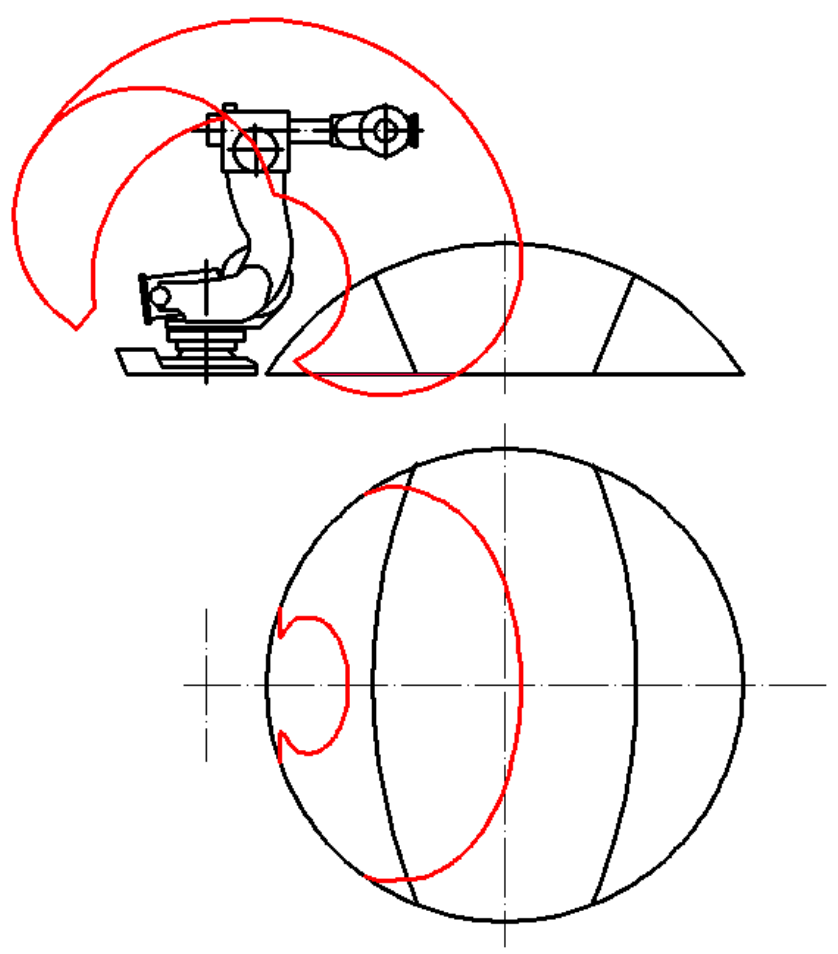

Fig. 7. The location of the seams on the bottom and the working area of the welding robot (in red).

On Fig. 7 shows the mutual position of the bottom before welding and the working area of the robot. In the side view, the sloping weld appears to fall entirely into the work area, but in the top view, there are two sections at the beginning and end of the weld that do not fall into the work area. To study and correct such situations, a mathematical model of the working area and the weld is necessary.

The developed mathematical model is based on a system of equations in which the geometric characteristics of the working area of the robot (the position of the robot relative to the bottom, the dimensions of the manipulator) and the geometric characteristics of the bottom with certain parameters of the weld (radius of the spherical surface, the height of the bottom, the slope of the weld plane relative to the axis of the bottom) are interconnected.

As initial data in this model the sizes of links of the manipulator, position of an axis of the robot concerning an axis of the bottom, diameter of the bottom, radius of a spherical surface of the bottom (in model the bottoms of the spherical form are considered only), an inclination angle of a plane of a welded seam of the bottom concerning an axis of the bottom are used. 


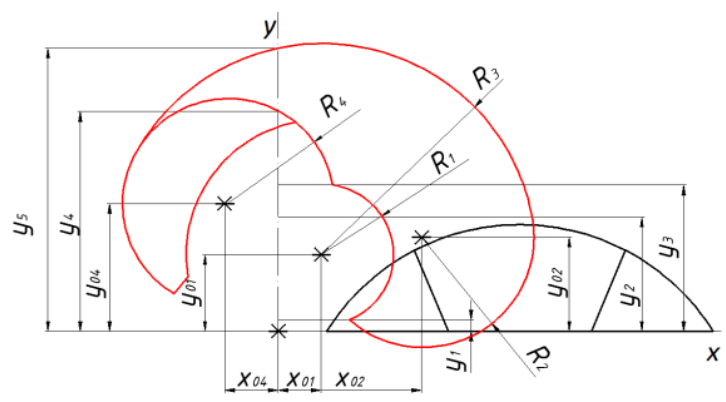

(a)
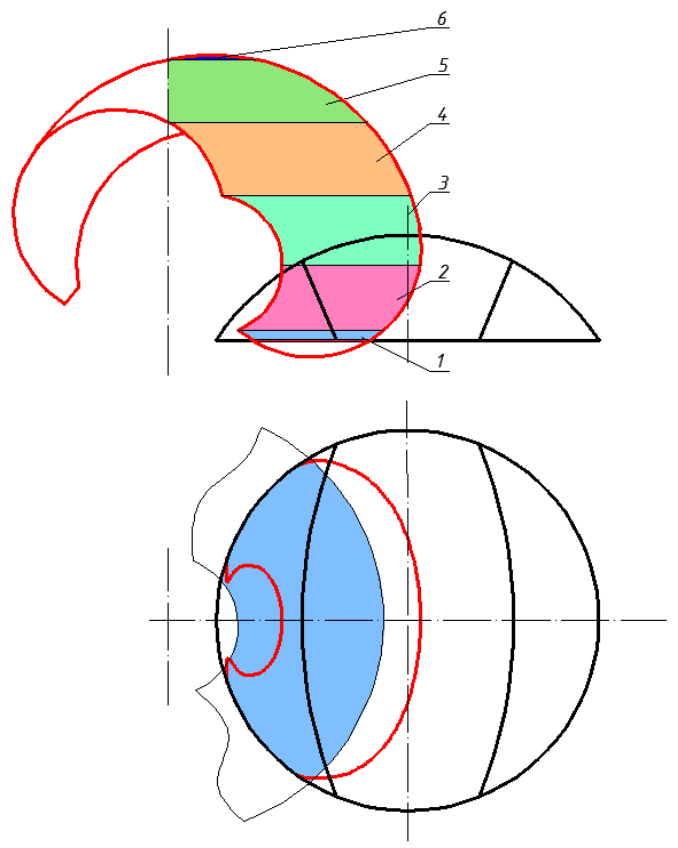

(b)

Fig. 8. Geometric interpretation of the mathematical model of obtaining a weld on the bottom with the help of an industrial robot: the profile of the bottom (a) and the layer-by-layer division of the working area of the robot (b).

On Fig. 8 presents a geometric interpretation of the mathematical model, which shows the working area of the robot [6], the profile of the bottom (Fig.8, a) with the coordinates of the centers of rotation of the individual parts of the manipulator, determining the position of the working area. On Fig. 8, b layers are shown in colors and indicated by numbers from 1 to 6 areas of the working area, which use different equations and boundary conditions. In the model (Fig.8, a) the $\mathrm{x}$-axis is directed to the right, the y-axis is up. The center of intersection of axes (coordinate center) is the intersection of the vertical axis of rotation of the robot with the lower reference plane of the robot. In certain nodal points relative to the center of coordinates there are centers of spherical and toroidal surfaces characterizing the near and far boundary positions of the manipulator head relative to this nodal point with coordinates $(\mathrm{x} 01, \mathrm{y} 01),(\mathrm{x} 02, \mathrm{y} 02),(\mathrm{x} 04, \mathrm{y} 04)$. At different heights relative to the floor, the robot's working area is described by different equations, since there are several centers of toroidal surfaces describing the near and far boundaries of the working zone. 
In overall, the working area is described by a system of inequalities

$$
x^{2}+z^{2}-r^{2}(y)<f(x, y, z)<x^{2}+z^{2}-R^{2}(y)
$$

where $x, y, z$-coordinates of the points of the working area, $r(y)$ - is the radius of the near zone boundary, $R(y)$ - is the radius of the far boundary of the zone, $f(x, y, z)$ - is a function describing the position of the curve.

For the specific robot model shown in Fig. 6, the following system of inequalities describing the position of the working area is proposed.

$$
\begin{aligned}
& \left\{\begin{array}{c}
y \epsilon\left[0 ; y_{1}\right] \\
x^{2}+y^{2}-\left(x_{02}-\sqrt{R_{2}^{2}-\left(y_{02}-y\right)^{2}}\right)^{2}<f(x, y, z) \\
x^{2}+y^{2}-\left(x_{02}+\sqrt{R_{2}^{2}-\left(y_{02}-y\right)^{2}}\right)^{2}>f(x, y, z)
\end{array}\right. \\
& \left\{\begin{array}{c}
y \epsilon\left(y_{1} ; y_{2}\right] \\
x^{2}+y^{2}-\left(x_{01}+\sqrt{R_{1}^{2}-\left(y_{01}-y\right)^{2}}\right)^{2}<f(x, y, z) \\
x^{2}+y^{2}-\left(x_{02}+\sqrt{R_{2}^{2}-\left(y_{02}-y\right)^{2}}\right)^{2}>f(x, y, z)
\end{array}\right. \\
& \left\{\begin{array}{c}
y \epsilon\left(y_{2} ; y_{3}\right] \\
x^{2}+y^{2}-\left(x_{01}+\sqrt{R_{1}^{2}-\left(y-y_{01}\right)^{2}}\right)^{2}<f(x, y, z) \\
x^{2}+y^{2}-\left(x_{01}+\sqrt{R_{3}^{2}-\left(y-y_{01}\right)^{2}}\right)^{2}>f(x, y, z)
\end{array}\right. \\
& \left\{\begin{array}{c}
\left.y \epsilon y_{4}\right] \\
x^{2}+y^{2}-\left(x_{04}+\sqrt{R_{4}^{2}-\left(y-y_{04}\right)^{2}}\right)^{2}<f(x, y, z) \\
x^{2}+y^{2}-\left(x_{01}+\sqrt{R_{3}^{2}-\left(y-y_{01}\right)^{2}}\right)^{2}>f(x, y, z)
\end{array}\right. \\
& \left\{\begin{array}{c}
y \epsilon\left(y_{4} ; y_{5}\right] \\
x^{2}+y^{2}-\left(x_{02}+\sqrt{R_{3}^{2}-\left(y-y_{01}\right)^{2}}\right)^{2}>f(x, y, z) \\
x^{2}+y^{2}-\left(x_{01}-\sqrt{R_{3}^{2}-\left(y-y_{01}\right)^{2}}\right)^{2}<f(x, y, z) \\
x^{2}+y^{2}-\left(x_{01}+\sqrt{R_{3}^{2}-\left(y-y_{01}\right)^{2}}\right)^{2}>f(x, y, z)
\end{array}\right.
\end{aligned}
$$

where $y_{1}, y_{2}, y_{3}, y_{4}, y_{5}$ - coordinates of boundary values of $y, x_{01}, x_{02}, x_{04}, y_{01}, y_{02}, y_{04}-$ position of centers of axes of toroidal surfaces, $R_{1}, R_{2}, R_{3}, R_{4}$ - radii of toroidal surfaces.

The system of inequalities (2) describes the lowest part of the robot's working area at $y \in\left[0 ; y_{1}\right]$, located directly at the lower boundary of the robot and the bottom, and painted in blue (Fig.8b). The height of this area of the work area is $y_{1}$. The first inequality of the system (2) describes the position of the far boundary of the working zone, and the second inequality describes the position of the near boundary of the working zone. The system of inequalities (3) describes the next region (sequence from bottom to top) of the robot's working area at $y \in\left(y_{1} ; y_{2}\right]$ and in this system, just as in (2) the first inequality describes the far boundary and the second the near boundary. Area 2 is painted pink in Fig.8b. The following areas have similar descriptions of the working area in inequality systems and are shown in Fig.8b: area 3 is green at $y \epsilon\left(y_{2} ; y_{3}\right]$, area 4 is brown at $y \epsilon\left(y_{3} ; y_{4}\right]$, area 5 is light-green at $y \epsilon\left(y_{4} ; y_{5}\right]$, area 6 is blue at $y \in\left(y_{5} ;+\infty\right)$. 

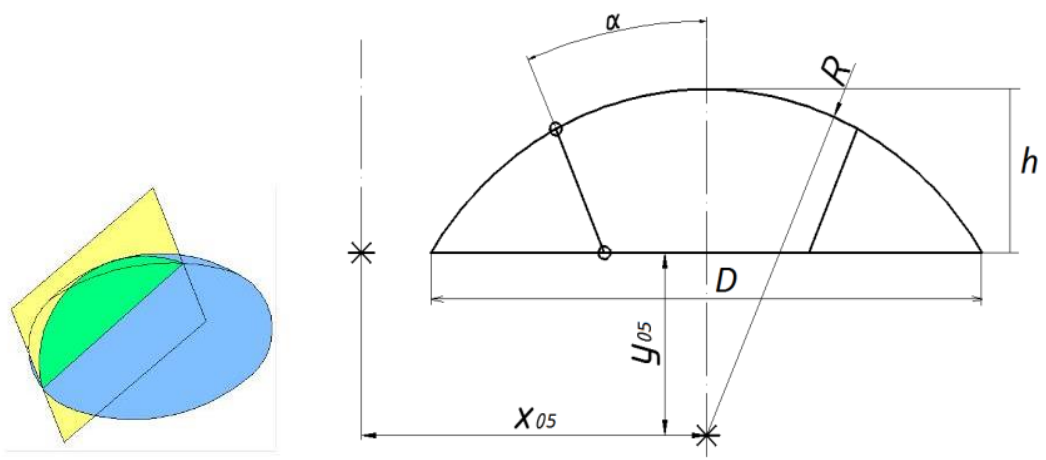

Fig. 9. Geometric model of the bottom with petal division.

On Fig. 9 shows a geometric model of the bottom, which has a division in the form of petals. Equation describing the surface of a sphere is presented:

$$
\left(x-x_{05}\right)^{2}+\left(y-y_{05}\right)^{2}+\left(z-z_{05}\right)^{2}-R^{2}=0
$$

Given that $\left(x-x_{05}\right)=\left(y-y_{05}\right) \cdot \operatorname{tg} \alpha$ and $z_{05}=0$ are obtain:

$$
\begin{gathered}
\left(y-y_{05}\right)^{2} \operatorname{tg}^{2} \alpha+\left(y-y_{05}\right)^{2}+z^{2}-R^{2}=0 \\
y= \pm \sqrt{\frac{R^{2}-z^{2}}{\operatorname{tg}^{2} \alpha+1}}+y_{05}
\end{gathered}
$$

where $x_{05}, y_{05}, z_{05}$ - coordinates of the position of the center of intersection of the axes of the bottom, $R$ - radius of the spherical surface of the bottom, $\alpha$ - angle of inclination of the weld.

\section{Results}

On the basis of the proposed model, the results of calculations for the boundaries of the near and far zone of the robot welding head and the coordinates of the weld bottoms with petal division were obtained.

The boundaries of the working area of the ESAB Rosio robot were used as initial data (Fig.8, a): $x_{01}=x_{03}=430 \mathrm{~mm}, x_{02}=1400 \mathrm{~mm}, x_{04}=540 \mathrm{~mm}, y_{01}=y_{03}=800 \mathrm{~mm}, y_{02}=950$ $\mathrm{mm}, y_{04}=1300 \mathrm{~mm}, y_{1}=100 \mathrm{~mm}, y_{2}=1150 \mathrm{~mm}, y_{3}=1500 \mathrm{~mm}, y_{4}=2200 \mathrm{~mm}, y_{5}=2900$ $\mathrm{mm}, R_{1}=700 \mathrm{~mm}, R_{2}=1000 \mathrm{~mm}, R_{3}=2000 \mathrm{~mm}, R_{4}=1000 \mathrm{~mm}$ (the centers of the axes of torus circles with radii $R_{1}$ and $R_{3}$ coincide, so $x_{01}=x_{03}$ и $y_{01}=y_{03}$ ). Table 1 shows the raw data for calculating the coordinates of the weld for the bottom reed articulation: the diameters of the lower edge of the bottom $D$, the radius of the spherical surface is $R$, the distance from the center of the sphere to the bottom surface of the bottom $y_{05}$, bottom height $h$. In the calculation was varied with the angle of inclination of the seam $\alpha$ in the range from $0^{0}$ to $53^{0}$ and the distance between the vertical axes of the robot's workspace and the bottom $\mathrm{x}_{05}$ in the range from 1600 to $2500 \mathrm{~mm}$. 
Table 1. The size of the bottoms with a petal division.

\begin{tabular}{|c|c|c|c|}
\hline $\mathbf{D}, \mathbf{m m}$ & $\mathbf{R}, \mathbf{m m}$ & $\mathbf{y} \mathbf{0 5}, \mathbf{m m}$ & $\mathbf{h}, \mathbf{m m}$ \\
\hline 1950 & 1240 & 600 & 480 \\
\hline 2300 & 1470 & 720 & 590 \\
\hline 2700 & 1700 & 845 & 695 \\
\hline 3100 & 1930 & 900 & 870 \\
\hline 3500 & 2160 & 1090 & 900 \\
\hline 4000 & 2200 & 1130 & 910 \\
\hline
\end{tabular}

Figure 10, a shows the far boundary of the robot's working area (rotated, the vertical axis of rotation of the robot in the figure is horizontal) and the far and near boundaries of the working area (Fig.10, b).

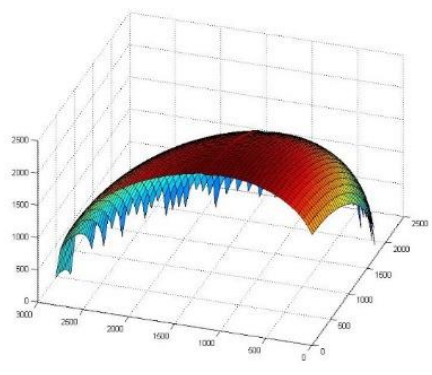

(a)

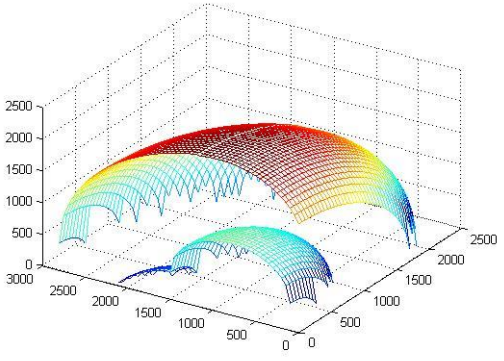

(b)

Fig. 10. The workspace of the robot (rotated): (a) the far boundary; (b) far and near the border.

Figure 11 shows an example of the intersection of a number of welds bottoms with petal partitioning with the working area at different angles of inclination of the weld (from 15 to 50 degrees).

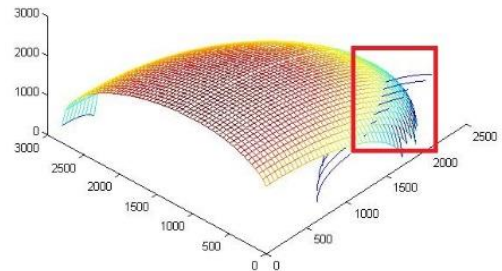

(a)

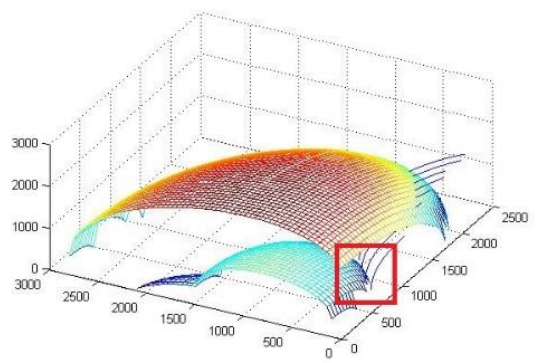

(b)

Fig. 11. An example of the intersection of welds bottoms with petal division with the working area of the robot.

Figure 11, a shows the intersection of the seams with the far boundary of the working area,and figure 11, b and the far and near boundaries of the working area of the robot. Welding is possible if the weld is located in the space between the near and far boundaries of the working area of the robot. If the seam crosses one of the boundaries, the welding head will not be able to continuously, without moving the workpiece, weld the seam area beyond the working area. 
Figure 11, a shows (red rectangle) that part of the trajectory of some welds cross the far boundary of the working area and, therefore, at this position of the bottom welding of the seam is impossible. In figure $11, \mathrm{~b}$, you can see that those welds that do not cross the far border of the working area can cross the near border (red rectangle), which also does not allow welding in the shown position.

Figure 12 shows the results of the calculation of valid values position of the bottom relative to the robot, shows the workspace of the robot and weld, passing completely inside the working area and not across its borders, allowing continuous welding of the parts.

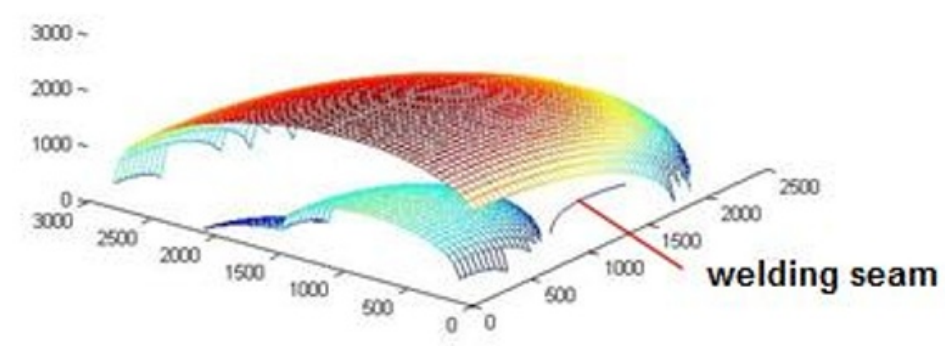

Fig. 12. The possible position of the weld relative to the working area of the robot, providing continuous welding.

The possible distance between the robot axis and the bottom axis for different diameters with different angles of inclination $\alpha$ of the weld is determined for the bottoms with petal division (Fig.13).

For a bottom with a local specified weld angle and diameter to ensure guaranteed welding, the minimum distance from the robot axis to the bottom axis is equal to the value on the lower branch of the graph curve, and the maximum distance is on the upper branch.

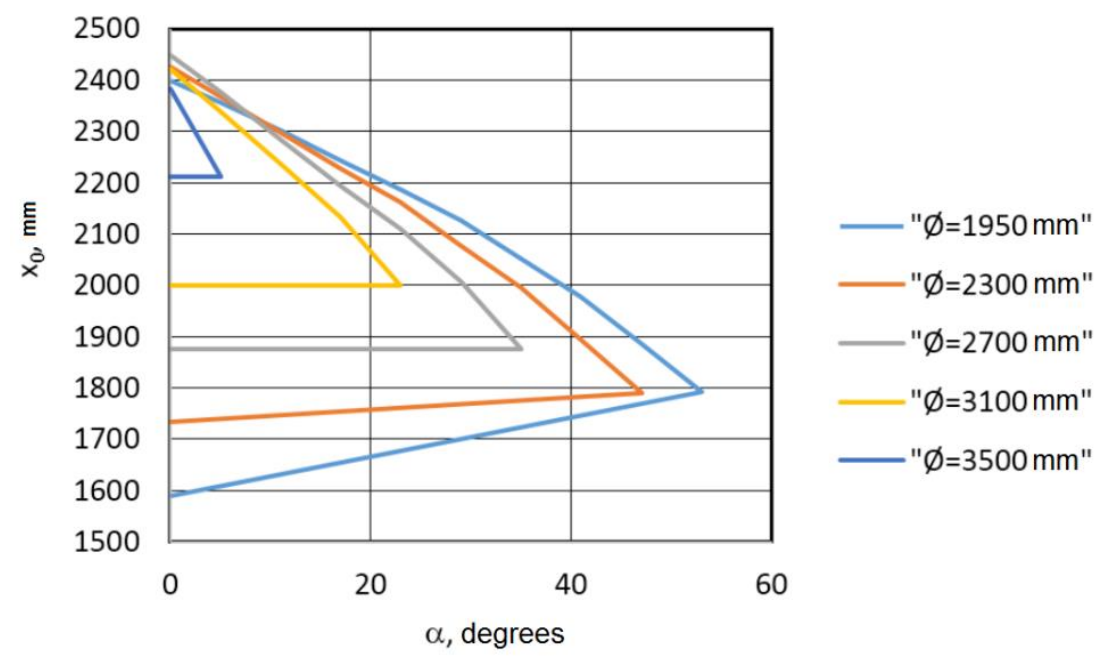

Fig. 13. Areas of possible location of the axis of rotation of the bottom and the axis of the robot at different angles of inclination for the bottoms of the petal division for different diameters.

For example, for a bottom with a weld angle $\alpha=20^{\circ}$ and a diameter of $2700 \mathrm{~mm}$, the distance between the bottom and robot axes should be between 1875-2150 mm. 


\section{Discussion and application in the education}

A further development of the proposed model for the description of spherical surfaces can be the use of vector calculus for problems of spherical geometry, and for the description of torus surfaces-quite simple analytical dependencies.

The considered model is widely used in the educational process of the Department of technologies of rocket and space engineering in the study of technological equipment of the welding process of the bottoms of rocket and space technology. The model is implemented in the software product MathLab and allows you to visualize the position of the robot, the bottom, the weld between them. Students build on the given geometric parameters of the working area of the robot, set the parameters of the bottom and determine the possibility of obtaining a continuous weld. By results build schedules and prepare the report.

\section{Conclusion}

The review of technological equipment for friction stir welding of sheet materials is carried out. The use of universal industrial robots equipped with a head for friction stir welding is proposed.

A mathematical model describing the geometry of the bottom and the working area of the robot is developed, which allows to determine the possibility and impossibility of welding a continuous seam for typical designs of the bottoms of rocket and space technology.

For bottoms with petal division, dependencies are proposed to determine the position of the robot relative to the bottom, providing friction stir welding of the continuous seam. This model is used in educational process in Bauman Moscow State Technical University for studying students on aerospace manufacturing.

\section{References}

1. R.S. Mishra, M.W. Mahoney, Friction Stir Welding and Processing, ASM International, p. 333 (2007)

2. A. Tongne, C. Desrayaud, M. Jahazi \& E. Feulvarch, On material flow in friction stir welded al alloys, Journal of Materials Processing Technology, 239, pp. 284-296 (2017). doi:10.1016/j.jmatprotec.2016.08.030

3. G. Wang, Y. Zhao \& Y. Hao, Friction stir welding of high-strength aerospace aluminum alloy and application in rocket tank manufacturing, Journal of Materials Science and Technology, 34(1), pp.73-91 (2018). doi:10.1016/j.jmst.2017.11.041

4. A.G. Boitsov, D.N. Kuritsyn, M.V. Siluyanova \& V.V. Kuritsyna, Friction stir welding in the aerospace industry, Russian Engineering Research, 38(12), pp. 1029-1033 (2018). doi:10.3103/S1068798X18120043

5. F.C. Liu, Y. Hovanski, M.P. Miles, C.D. Sorensen \& T.W. Nelson, A review of friction stir welding of steels: Tool, material flow, microstructure, and properties, Journal of Materials Science and Technology, 34(1), pp. 39-57 (2018). doi:10.1016/j.jmst.2017.10.024

6. J. Liu, Application and development of friction stir welding technology in high speed EMU manufacturing, China Welding (English Edition), 27(4), pp. 57-62 (2018). doi:10.12073/j.cw.20180705001

7. G.K. Padhy, C.S. Wu \& S. Gao, Friction stir based welding and processing technologies - processes, parameters, microstructures and applications, Journal of Materials Science and Technology, 34(1), pp. 1-38 (2018). doi:10.1016/j.jmst.2017.11.029 
8. V.V. Khanin, P.V. Kruglov, Estimation of technological possibilities of branch pipes welding on bottoms of rocket_space products by friction stir welding, Izvestia vuzov. Seriya Mashinostroenie, № 7, pp.67-71 (2012).

9. A.G. Ponarin, P.V. Kruglov, Features of Manufacturing Bottoms and Rocket Tank Bodies Using Friction Stir Welding, Aerospace scientific journal, №2 (2015). DOI: 10.7463/aersp.0215.0789685.

10. Product brochure Nova-tech Engineering. URL: http://www.ntefsw.com/product_brochures.htm (access at 09.12.2019).

11. Friction Stir Welding. Manufacturing Technology (MTI). URL: https://www.mtiwelding.com/technologies/friction-stir-welding/ (access at 09.12.2019).

12. Rosio, Friction Stir Welding Robot for welding of challenging joints. URL: http://products.esab.com/ESABImages/rosio_XA00133620_cze.pdf (access at 09.12.2019).

13. B.S. Cota, A.Q. Bracarense \& F.G.F. Coelho, Sizing of a robot system for joining by friction stir welding process, [Dimensionamento de um sistema robotizado para a soldagem pelo processo friction stir welding] Soldagem e Inspecao, 22(4), pp. 480-493 (2017). doi:10.1590/0104-9224/SI2204.07

14. K. Kolegain, F. Leonard, S. Zimmer-Chevret, A.B. Attar \& G. Abba, A feedforward deflection compensation scheme coupled with an offline path planning for robotic friction stir welding, IFAC-PapersOnLine, 51(11), pp. 728-733 (2018). doi:10.1016/j.ifacol.2018.08.405

15. F. Lijin \& S. Longfei, Design of a novel robotic arm with non-backlash driving for friction stir welding process, International Journal of Advanced Manufacturing Technology, 93(5-8), pp. 1637-1650 (2017). doi:10.1007/s00170-017-0617-2

16. T. Oka, Robot friction stir welding system, Yosetsu Gakkai Shi/Journal of the Japan Welding Society, 87(8), pp. 552-554 (2018). doi:10.2207/jjws.87.552

17. T. Sun, H. Wu, B. Lian, Y. Qi, P. Wang \& Y. Song, Stiffness modeling, analysis and evaluation of a 5 degree of freedom hybrid manipulator for friction stir welding, Proceedings of the Institution of Mechanical Engineers, Part C: Journal of Mechanical Engineering Science, 231(23), pp. $4441-4456$ (2017). doi:10.1177/0954406216668911

18. M. Wan, W. Zhou, H. Luo \& Y. Tian, Design and motion control of the high precision heavy load friction stir welding robot, [高精度重载搅拌摩擦焊机器人设计与运动控 制] Jiqiren/Robot, 40(6), pp. $817-824$ and p. 834 (2018). doi:10.13973/j.cnki.robot. 170560

19. I. Zybin, K. Trukhanov, A. Tsarkov \& S. Kheylo, Backing plate effect on temperature controlled FSW process, Paper presented at the MATEC Web of Conferences, p. 224 (2018). doi:10.1051/matecconf/201822401084

20. A.S. Chernyatin, Y.G. Matvienko, I.A. Razumovsky, Fatigue surface crack propagation and intersecting cracks in connection with welding residual stresses, Fatigue Fract Eng Mater Struct 2018; 41(10) (2018):2140-52.

21. V.V. Kovalev, R.S. Mikheev, N.V. Kobernik, A.L. Galinovskiy, I.V. Ershov, Formation of an intermetallic layer during arc facing of aluminum alloys onto a steel substrate, Russ Metall (Metally) 2017, 2017(13), pp. 1118-24 (2017)

22. B.F. Yakushin, A.V. Bakulo, I. N. Shiganov, Improving of weldability of heatstrengthened aluminum alloys, Tsvetn Met, 2016(5), pp. 79-84 (2016)

23. A.S. Chernyatin, Y.G. Matvienko \& I.A. Razumovsky, Fatigue surface crack propagation and intersecting cracks in connection with welding residual stresses, 
Fatigue and Fracture of Engineering Materials and Structures, 41(10), pp. 2140-2152 (2018). doi:10.1111/ffe.12808.

24. S. Chen, Y. Zhou, J. Xue, R. Ni, Y. Guo \& J. Dong, High rotation speed friction stir welding for 2014 aluminum alloy thin sheets, Journal of Materials Engineering and Performance, 26(3), pp. 1337-1345 (2017). doi:10.1007/s11665-017-2524-y

25. Q. Chu, X.W. Yang, W.Y. Li, A. Vairis \& W.B. Wang, Numerical analysis of material flow in the probeless friction stir spot welding based on coupled eulerian-lagrangian approach, Journal of Manufacturing Processes, 36, pp. 181-187 (2018). doi:10.1016/j.jmapro.2018.10.013. 